\title{
Social support of athletes in the sport of the blind (on the example of mini-football $5 \times 5$ B1)
}

\author{
Alexander Zhalilov ${ }^{1 *}$, Sergey Evseev ${ }^{2}$, Olga Evseeva $^{2}$, Alexander Makhov $^{1}$ \\ ${ }^{1}$ Russian State Social University, 129226 Moscow, Russia \\ ${ }^{2}$ National State University of Physical Culture, Sports and Health named after P.F. Lesgaft, 190121, Saint Petersburg, Russia
}

\begin{abstract}
This article discusses the social support of totally blind football players. A range of issues related to educational and creative activities, as well as leisure activities for young athletes with visual impairments are discussed. The functions of a tutor and a social worker who provide social support for young athletes, the importance and significance of their direct responsibilities, and the most relevant activities that they perform are revealed.
\end{abstract}

\section{Introduction}

Currently, adaptive sports are actively developing in Russia. They are represented by a variety of disciplines among people with various types of health disorders - sensory, musculoskeletal, mental, and others [1-4]. According to Russian scientists, adaptive sports help people with disabilities feel like a full-fledged member of society, develop their psychophysical capabilities, achieve success in their chosen sports specialization, and develop their talents both in the sports arena and in other activities [1,2, 5-7]. In addition, the social circle of communication is expanding for a person who has certain deviations in the state of health It has a positive impact on his psychoemotional state. Athletes who have certain types of health disorders actively communicate with their own circle of athletes, with competition organizers, judges, fans and other people. Recognition of an athlete's achievements in various sports activities for people with disabilities raises the status of such competitions and strengthens the athletes ' faith in their abilities [1,5].

The adaptive sports, as well as high-performance sports among healthy athletes, require a well-organized training process, a high level of athletes' technical and tactical skills development, especially during the preparation for competitions. Competition in adaptive sports increases from year to year. The coaching staff needs to apply new techniques and technologies for their athletes [2,7]. In our study, we will pay attention to such an unusual sport for people with visual impairments as mini-football for the blind 5x5 (B1) (sport for the blind). This team sport successfully began its development at the end of the last century. The various categories of social workers contribute to the achievements in sports activities of blind athletes.

\section{Materials and methods}

Mini-football for the blind 5x5 (B1) develops for several decades. The first world championship in this sport was held in 1998. The Russian national 5x5 (B1) mini-football team actively participates in many international competitions. It becomes a prize-winner of significant tournaments and shows good results [8,9]. In 2015 the national team won silver medals at the European Championship, and in 2017 it won gold medals for the first time. They earned the right to participate in the world championship.

There are various international tournaments, all-Russian and regional competitions that allow athletes with visual impairment to show their skills [10-12].

In addition to competitive activities, various social services provide a large support for athletes in sports for the blind, such as: support to the place of training and back, organization of living conditions at the place of residence (eating, performing hygiene procedures, etc.), bringing to a sports dispensary for in-depth medical examination, organization of medical care, leisure activities on free days (exhibitions, concerts, forums), assistance in organizing travel abroad (registration of documents, delivery to the airport, railway station). The great amount of work forces specialists of various specialties to join in.

This study examines the social support of the blind football players team from Russian state social University. It performs successfully at regional, national and international tournaments for few years. The team's players are part of the Russian Federation national in this sport. The athletes with this pathology perform a number of additional functions necessary for a comfortable life. Most of this team lives in a hostel near the sports base, where the training

\footnotetext{
* Corresponding author: bonifacii1977@ mail.ru
} 
process takes place. One tutor and a social worker work with the team in the public housing building to help athletes in various domestic and social situations. Most of the work is performed by a social worker whose responsibilities include:

1) accompanying athletes to the training area and back;

2) escort to the place of study and back;

3) preparing afternoon tea and dinner;

4) the conduct of home exercises in subjects;

5) cleaning rooms;

6) purchase of food and basic necessities;

7) organization of athletes' active leisure (trips to sports matches, exhibitions, cafes, theaters);

8) organization of trips to medical institutions, social protection agencies, etc.

The role of the tutor is less global, but it is also necessary and consists of the following functions:

1) help in small domestic situations;

2) assistance in completing the necessary training documents;

3) consultations on educational issues;

4) organization of educational work;

5) in the absence of a social worker, partially performing his duties.

The role of a social worker and tutor is quite broad. It requires the constant presence of these persons for the full life of blind athletes. The activities of these peple are designed in such a way that during extracurricular hours from 16.00 to 23.00 , one of them must be in the hostel and provide the necessary assistance to blind athletes. From 7.00 to 8.30 the time period when football players wake up and go to school. Such a schedule for social workers allows the most rational construction of social support for blind athletes.

The blind athletes successfully receive an education: three people-higher education at the Russian state social University and four specialized secondary education at the RSSU College. Such a rational combination of sports and educational activities allows to educate full-fledged members of society. They will later be able to work fully in professions where good eyesight is not required. Many higher and secondary specialized educational institutions create the necessary conditions for students with various types of nosology to study leveling out health restrictions. There is also an inclusive education, which contributes to the successful development of academic disciplines, both for disabled and healthy citizens.

A social worker plays an important role in independent training of students in educational activities. He conducts daily classes with blind athletes. Most of the material in the subjects is studied using the verbal method. The socialworker reads the material for athletes. Braille is used for performing written and practical tasks which allow young athletes to complete successfully the material (laboratory work, essays, essays, lectures) in the disciplines. A wide variety of modern technologies are used. Installing programs in computers and phones allow studying educational subjects for blind citizens, as well as freely accessing the Internet and receiving information from various sources.

It is worth saying about such an important aspect of the young athletes' activity as creativity. Despite daily training and significant load, two of the guys engage in vocals. They successfully perform at various concerts, holidays and win prizes. For children with visual impairment, their creative activity is a kind of outlet. It's a specific social field in which their vocal talents are recognized. Athletes actively participate in the social life of the University, try themselves in creative competitions and concerts ("Student spring"," freshman Day", etc.). In 2019 one of the team's players became a participant of the pop art international festival "Moscow-transit". He won in the category " Vocal genre. Stage. Solo " "The Grand Prix of the festival".

\section{Results and discussion}

The research material shows that social support for football players with visual impairment includes such important aspects as:

- help with organizing the training process;

- performing work on independent training in educational activities;

- organization of leisure activities;

- assistance in the creative abilities development;

- assistance at the check-out athletes to international tournaments.

The range of a social worker and tutor responsibilities is quite wide and requires constant attention to the personality of young athletes. He must be able to find a non-standard approach to performing various life situations, to make more accessible the usual function (to walk to the University, stop, fill out documents, etc.) for a blind football player. The work schedule of these employees is irregular and forces them to perform some functions for blind athletes, despite the daily employment in other fields of activity.

The close interaction of the coaching staff with a social worker and a tutor allows to achieve the necessary sports results, especially when preparing for significant tournaments. Training activity is a complex and long process. There are no details, when working with the category of athletes with visual impairments. A well-planned and implemented training plan, organization of active recreation and recovery procedures, a rational training regime and training activities, a positive emotional attitude, an individual approach to each athlete all these together allow to prepare the team for the main starts of the season. Mini-football for visually impaired people is a team game. Well 
players' interaction on and off the sports field ultimately affects the sports result. Only the joint team work of the coaching staff, players with visual impairments, a social worker and a tutor can bring good results.

\section{Conclusions}

Based on the results of the study, we can say that the social support of football players with visual impairment $(5 \times 5$ B1) is very important in the life of young athletes. It helps to solve necessary points:

- support for training, study;

- trips to the theater, exhibitions, sports events;

- support to medical institutions (sports dispensaries);

- performing household services;

- assistance in escorting to the airport, railway station when leaving for international tournaments.

It is difficult to overrate the role of a tutor and a social worker. The range of their direct responsibilities solves a lot of problems. Both employees work at least eight hours a day with blind athletes. If necessary, the working time may increase due to various domestic or social circumstances. This category of employees closely interacts with the coaching staff of the national team, as many points related to the training process organization are also included in the list of their duties. The result of their activities helps to educate a socially active citizen of the country.

\section{References}

1. S.P. Evseev, O.E. Evseeva, Physical culture and health, 2015

2. S.P. Evseev, O.E. Evseeva, Theory and practice of physical culture, 2016

3. A.V. Zhalilov, A.S. Makhov, Theory and practice of physical culture, 2020

4. A.V. Zhalilov, I.S. Mironov, Research Journal of Pharmaceutical, Biological and Chemical Sciences, 2018

5. A.S. Makhov, In the world of scientific discoveries, 2011

6. Z.M. Kuznetsova, Y.D. Ovchinnikov, The Russian Journal of Physical Education and Sport, 13(1), 178-183 (2018). DOI: 10/14526/01_2018_298

7. A.S. Makhov, Adaptive physical culture, Saint Petersburg, 2017

8. K.S. Popenko, A.S. Makhov, Physical culture: education, training, 2018

9. K.S. Popenko, A.S. Makhov, Adaptive physical culture, 2018

10. K.S. Popenko, A.S. Makhov, Problems of development of Paralympic mini-football (sport of the blind) in Russia on the example of the Republic of Mari El $(212-217,2018)$

11. K.S. Popenko, A.S. Makhov, Adaptive physical culture, 2019

12. K.S. Popenko, A.S. Makhov, Current state of mini-football $5 \times 5$ (B1) (sport of the blind) in Russia ("La Prensa" Medica Argentina, 2018) 